\title{
A Chemical Lost Circulation Agent for Severe Leakage in Drilling
}

\author{
Kaihe Lv ${ }^{*}$, Hanyi Zhong and Guanlong Ren \\ School of Petroleum Engineering, China University of Petroleum, Qingdao, 266580, China
}

\begin{abstract}
This study presents a chemical lost circulation agent with some distinct advantages that make it suitable for use in controlling severe leakage during drilling process. It is a granular solid with irregular shape and able to bridge or fill the cracks and other porous or faulty formations into where the drilling fluid is lost. Then this agent will undergo a chemical reaction with water, and the reaction products fill between particles and bind tightly lost circulation agent particles to each others or to the rocks at the lost circulation zone, thus effectively enhance the compressive strength of the cementing body formed by the agent and prevent lost circulation. Temperature, particle size, and additives added have been shown to have a significant influence on the consolidating rate and compressive strength of the cementing body. In addition, the cementing body has certain permeability, and the permeability can be adjusted, so this agent is proper for use to control lost circulation in reservoir.
\end{abstract}

Keywords: Drilling, leakage, lost circulation agent, mechanism.

\section{INTRODUCTION}

Lost circulation is a common and complex problem that has deleterious, and sometimes even disastrous consequences for drilling operations. Since the 1960's China started to study some fundamental lost circulation materials and during that stage only one single material is used during lost circulation, after the 1990's people paid more attention to the serialization and standardization of lost circulation materials and in order to improve the efficiency of plugging compound lost circulation materials started to use. Main results are the polymer lost circulation treating agents, and inorganic lost circulation materials mainly composed of cement, including all kinds of special cement and mixed thick slurries, and temporary plugging additives, and compound plugging materials which composed of all kinds of inert bridging material and additives with different particle sizes and distribution [1-4]. A common chemical lost circulation material is often expensive and the cost is higher, and conventional plugging materials cannot effectively plug the malignant leakage such as cave. Other countries studied the loss and loss circulation control mechanism during drilling earlier: the former Soviet Union developed the plugging agent series based on urea resin and phenolic resin, and propylene polymers plugging agent series, and plugging agent slurry based on the latex [5]. In UK Brent oil field have developed a new type modified fiber material made up of fiberglass coated with surfactant and dispersant, which can resist high temperature of $232^{\circ} \mathrm{C}$, and solve the problems of lost circulation in that region [6]. Phillips Company developed a high filtration lost circulation material called DiasealM which can permeate into the formation and then filtrate quickly under the action of pressure difference, and

*Address correspondence to this author at the School of Petroleum Engineering, China University of Petroleum, Qingdao, 266580, China; Tel: 0086-546-8392274; Fax: 0086-546-8394600;

E-mail:1kh54321@126.com solid-phase in the liquid gathered thicker and thicker, and formed filter cake, and then compacted the leakage channels [7]. M-I developed crosslinking bridge series products such as PLUG FORM-A-PLUG [8]. Recent years there appeared hot-melt rubber plugging agent, expanded granular plugging agent, shear thickening fluid plugging agent, oil absorption solid material plugging agent, olefin plugging agent and absorbent polymer plugging agent and so on, and these agents can effectively solve the leakage problem of permeable formation and micro cracks formation, but they cannot solve the serious leakage such as natural fracture holes, holes or cave formation.

A variety of methods have been developed in an attempt to deal with such a problem. One of the most commonly used methods is to place bridging materials into the leakage zone [9-14]. These materials act to bridge or seal the cracks, crevices, fissures, or other porous or faulty formations into where the drilling fluid is lost, thereby forming a barrier for preventing further loss of the drilling fluid [15-19]. Such materials, however, have proved deficient in one or more respects. With rare exceptions, most of them are not effective in binding to each other or to the formations without actually forming an effective seal, thus they have a tendency to deteriorate under high pressure, and for the same reason lost circulation is likely to recur. In addition to such particulate based treatments, cement may be another option to seal off the leakage zone. The cement slurry, commonly prepared by mixing cement powder with water, is forced into the problem formation and allowed to solidify therein. However, there are many factors that have been suggested to have a potential for the performance of the cement slurry. It is often difficult for the cement slurry to stay at the desired location before the completion of the sealing off operation. Instead, it tends to pass into the crevices of the porous or cracked formation. Or it may become diluted by formation water so that solidification of the cement slurry might be prolonged or even unattainable. Given these practical considerations, it is 
necessary to precisely control the injection time of the cement slurry. This is, however, very difficult to achieve in reality.

Accordingly, there exists a continuing need for new and improved lost circulation materials. This study presents a novel self-binding lost circulation agent having some distinct advantages that make it suitable for use in controlling severe leakage. This granular material can effectively bridge or seal the problem formations. Additionally, it may react with water, and the reaction product can bind tightly lost circulation agent particles to each other or to the rocks at the lost circulation zone, thus effectively enhancing the compressive strength of the cementing body formed by the agent.

\section{PREPARATION AND PHYSICAL AND CHEMICAL PROPERTIES OF THE PROPOSED SELF-BINDING AGENT}

\subsection{Preparation Procedures}

The raw materials, mainly bauxite, limestone and gypsum, were sintered at $1000-1400^{\circ} \mathrm{C}$ for a given period of time, and the products were ground into powders with a required particle size and then mixed with a certain amount of additives.

\subsection{Physical and Chemical Properties}

\subsubsection{Appearance Characteristics}

The agent is finely granular and relatively chemically inert at room temperature and dry conditions.

\subsubsection{Distribution of the Particle Sizes}

The distribution of the particle sizes was determined by screening $500 \mathrm{~g}$ of the target sample for $5 \mathrm{~min}$ using an electric vibrating screen, and then the mass of the agent with varying particle sizes, as well as their mass percentage, was measured respectively. It shows that about $49.8 \%$ of the agent has a particle size of $0.4-0.6 \mathrm{~mm}$ and $30.1 \%$ has a particle size of $0.8-1.0 \mathrm{~mm}$, with the remainder having a particle size outside the above-defined range. In practical application, however, it is necessary to prepare different selfbinding agents with different particle sizes according to the actual conditions of the lost circulation zone, and this will be further discussed in the following sections.

\subsubsection{Density}

Mathematically, the density of the agent is defined as mass divided by volume:

$\rho=m / V$

where $\rho$ is the density $\left(\mathrm{g} / \mathrm{cm}^{3}\right), \mathrm{m}$ is the mass $(\mathrm{g})$ and $\mathrm{V}$ is the volume of the agent $\left(\mathrm{cm}^{3}\right)$.

In this study, mass was measured using a balance scale, and volume using the following procedure: put the agent in a measuring cylinder that was vertically positioned, then pour distilled water slowly into the cylinder until it completely submerged the agent without overflow, record the volume of the distilled water added $(\mathrm{Vb})$ and the total volume of the agent and water (Vo). Then the volume of the agent was the difference between $\mathrm{Vo}$ and $\mathrm{Vb}(\mathrm{V}=\mathrm{Vo}-\mathrm{Vb})$. The density of the self-binding agent measured in this way is $1.075 \mathrm{~g} / \mathrm{cm}^{3}$.

\section{BINDING PERFORMANCE OF THE SELF- BINDING LOST CIRCULATION AGENT}

The agent was packed into a $\varphi 25 \times 30 \mathrm{~mm}$ glass tube with an opening at the top, then the tube was completely immersed in a thermostatic water bath. It underwent a hydrolysis reaction with water at various temperatures for varying periods of time to form cementing body. At the completion of curing, the glass tube was broken gently to remove the cementing body. Finally, the cementing body was grounded at both ends, dried in an incubator at $40^{\circ} \mathrm{C}$ for $24 \mathrm{~h}$, and then reserved for future use.

\subsection{The Effects of Temperature and Time}

Due to the strength of the new chemical cementing agent is affected by temperature and time, and the influence of the two factors are mutually, the change of the chemical cementing agent strength under different temperature and time was considered.

The cementing body was formed at different temperatures $\left(50^{\circ} \mathrm{C}, 70^{\circ} \mathrm{C}, 90^{\circ} \mathrm{C}\right.$ and $\left.120^{\circ} \mathrm{C}\right)$ for different periods of time $(2 \mathrm{~h}, 4 \mathrm{~h}, 6 \mathrm{~h}, 12 \mathrm{~h}, 18 \mathrm{~h}$ and $24 \mathrm{~h})$, and the resulting compressive strength is shown in Table 1. Temperature and curing time have been shown to have a significant effect on the compressive strength of the cementing body formed by the self-binding agent. Specifically, high temperature appears to be beneficial for the formation of the cementing body. In addition, curing time can also be a critical factor affecting the compressive strength of the cementing body, the longer the curing time, the better the compressive strength of the cementing body. These findings have important implications for the determination of the injection and curing time of the lost circulation agent.

Table 1. Compressive Strength of the Cementing Body Formed at Different Temperatures for Different Periods of Time (MPa)

\begin{tabular}{|c|c|c|c|c|}
\hline \multirow{2}{*}{ Time (h) } & \multicolumn{4}{|c|}{ Temperature ( ${ }^{\circ}$ C) } \\
\cline { 2 - 5 } & $\mathbf{5 0}$ & $\mathbf{7 0}$ & $\mathbf{9 0}$ & $\mathbf{1 2 0}$ \\
\hline \hline 2 & $\times$ & $\times$ & $\times$ & 0.82 \\
\hline 4 & $\times$ & $\times$ & 0.52 & 2.35 \\
\hline 6 & $\times$ & 0.53 & 0.86 & 3.02 \\
\hline 12 & 0.47 & 2.91 & 3.05 & 3.51 \\
\hline 18 & 2.47 & 4.76 & 4.91 & 5.06 \\
\hline 24 & 4.32 & 5.34 & 5.41 & 5.73 \\
\hline
\end{tabular}

Note: $\times$ represents that the compressive strength of the cementing body is too low to be measured, or that the self-binding agent fails to consolidate.

\subsection{The Effects of Particle Size}

By the test result of particle size distribution above, the particle size distribution of general new chemical plugging 
agent was: particle size of $0.4-0.6 \mathrm{~mm}$ is $20 \%$, particle size of $0.6-0.8 \mathrm{~mm}$ is $49.8 \%$, particle size of $0.8-1.0 \mathrm{~mm}$ is $30.1 \%$, others are $0.1 \%$. For cementing agents with different particle sizes, the compressive strength changed with temperature and time. As can been seen from the test results of Tables 2-6, under a certain temperature the strength of the cement gradually increased with the increase of time. Under a certain time, the strength of the cement gradually increased with the increase of temperature. This is because as the particle size decreases, the pore between cement particles decreases which is equal to the increasing of cement density. So the compressing strength increases. According to downhole conditions in the field application, it can get cement with different compressive strength by adjusting the particle size distribution and then can realize the goal.

The agent was milled to fine powders using a mill. The particles ranging from $0.15 \mathrm{~mm}$ to about $1.0 \mathrm{~mm}$ were tested, and the results were shown in Tables 2-6. As shown in Tables 2-6, given the same temperature and the same time. Those with a particle size of $0.15-0.25 \mathrm{~mm}$ and $<0.15 \mathrm{~mm}$ were tested, and the results are shown in Tables $\mathbf{2}$ and $\mathbf{3}$ respectively. Given the same temperature and time, the agent with a particle size of $<0.15 \mathrm{~mm}$ exhibits a better compressive strength than that with a particle size of 0.15 $0.25 \mathrm{~mm}$. Thus it is imperative to mill the agent into fine powders, which is thought to be able to improve the compressive strength of the cementing body and decrease significantly the time needed to consolidate. This prompts us to choose a proper particle size based on a thorough consideration of the location and temperature of the lost circulation zone.

In all the tests, $\times$ represents that the compressive strength of the cementing body is too low to be measured, or that the self-binding agent fails to consolidate.

Table 2. Compressive Strength of Cementing Body of SelfBonding Lost Circulation Agent (0.8 1.0mm)/MPa

\begin{tabular}{|c|c|c|c|c|}
\hline Time $(\mathrm{h}) \quad$ Temperature $\left({ }^{\circ} \mathrm{C}\right)$ & 50 & 70 & 90 & 120 \\
\hline 2 & $\times$ & $\times$ & 1.02 & 1.20 \\
\hline 4 & $x$ & 0.28 & 2.75 & 2.87 \\
\hline 6 & 0.57 & 1.02 & 3.07 & 3.14 \\
\hline 12 & 0.95 & 2.31 & 4.58 & 4.86 \\
\hline 18 & 2.57 & 3.78 & 5.69 & 5.94 \\
\hline 24 & 3.89 & 5.12 & 7.22 & 7.53 \\
\hline
\end{tabular}

\subsection{The Effects of Additives Used}

The additives are expected to be able to improve the hydrolysis and consolidation rate of the agent, and also to improve the initial and final strength of the cementing body. However, such effect depends critically on which additive is used. In this study, the compressive strength of the cementing body formed by a mixture of the agent with a particle size of $\leq 0.15 \mathrm{~mm}$ and different additives, e.g. calcium chloride $\left(\mathrm{CaCl}_{2}\right)$, triethanolamine, or both, at $70^{\circ} \mathrm{C}$ for $2 \mathrm{~h}$ was tested and compared, and the results are shown in
Table 7. As expected, the addition of $1.0 \%$ calcium chloride or $0.2 \%$ triethanolamine into the self-binding agent leads to a higher compressive strength of the cementing body as compared with that without any additives. The former, however, seems to be somewhat better than the latter. The mechanism through which the additives improve the compressive strength of the cementing body might be that more reaction products (that act as binder) are formed due to the enhanced hydrolysis rate of the agent, as stated previously. And can be seen from Table 7 calcium chloride and triethanolamine can create synergies to make the compressive strength higher.

Table 3. Compressive Strength of Cementing Body of SelfBonding Lost Circulation Agent (0.6 0.8mm)/MPa

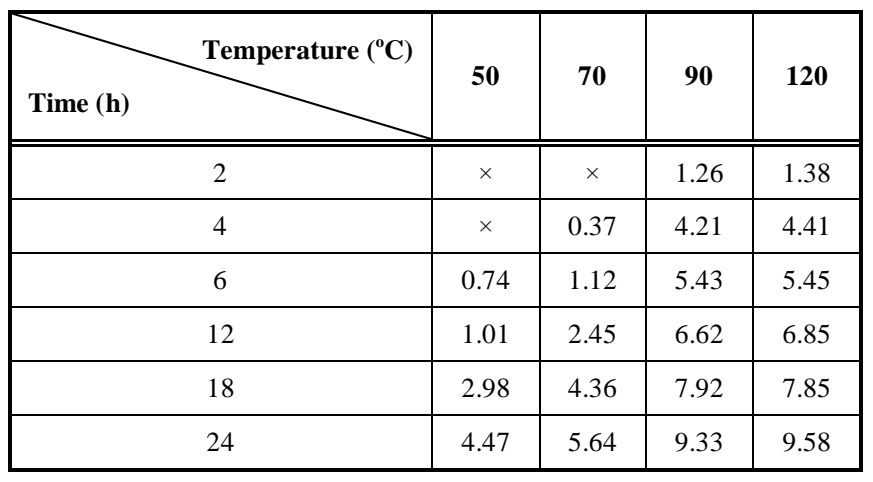

Table 4. Compressive Strength of Cementing Body of SelfBonding Lost Circulation Agent (0.4 0.6mm)/MPa

\begin{tabular}{|c|c|c|c|c|}
\hline${ }_{\text {Time(h) }}$ Te & 50 & 70 & 90 & 120 \\
\hline 2 & $x$ & $x$ & 1.61 & 2.13 \\
\hline 4 & 0.13 & 0.48 & 5.21 & 5.45 \\
\hline 6 & 1.14 & 1.23 & 6.68 & 6.79 \\
\hline 12 & 1.28 & 2.67 & 7.59 & 7.95 \\
\hline 18 & 3.27 & 4.76 & 9.22 & 9.35 \\
\hline 24 & 5.62 & 6.34 & 10.45 & 10.58 \\
\hline
\end{tabular}

Table 5. Compressive Strength of Cementing Body of SelfBonding Lost Circulation Agent (0.15 0.25mm)/ MPa

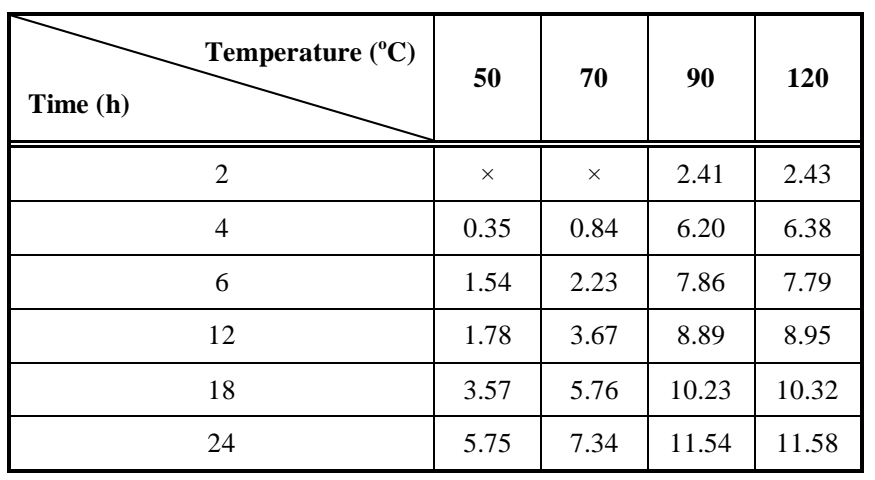


Table 6. Compressive Strength of the Cementing Body Formed by the Self-Binding Agent with a Particle Size of $<0.15 \mathrm{~mm} / \mathrm{MPa}$

\begin{tabular}{|c|c|c|c|c|}
\hline \multirow{2}{*}{ Time (h) } & \multicolumn{5}{|c|}{ Temperature $\left({ }^{\circ} \mathbf{C}\right)$} \\
\cline { 2 - 5 } & $\mathbf{5 0}$ & $\mathbf{7 0}$ & $\mathbf{9 0}$ & $\mathbf{1 2 0}$ \\
\hline \hline 2 & 6.24 & 7.03 & 9.04 & 9.43 \\
\hline 4 & 7.62 & 8.11 & 10.12 & 10.38 \\
\hline 6 & 9.01 & 9.7 & 10.34 & 11.09 \\
\hline
\end{tabular}

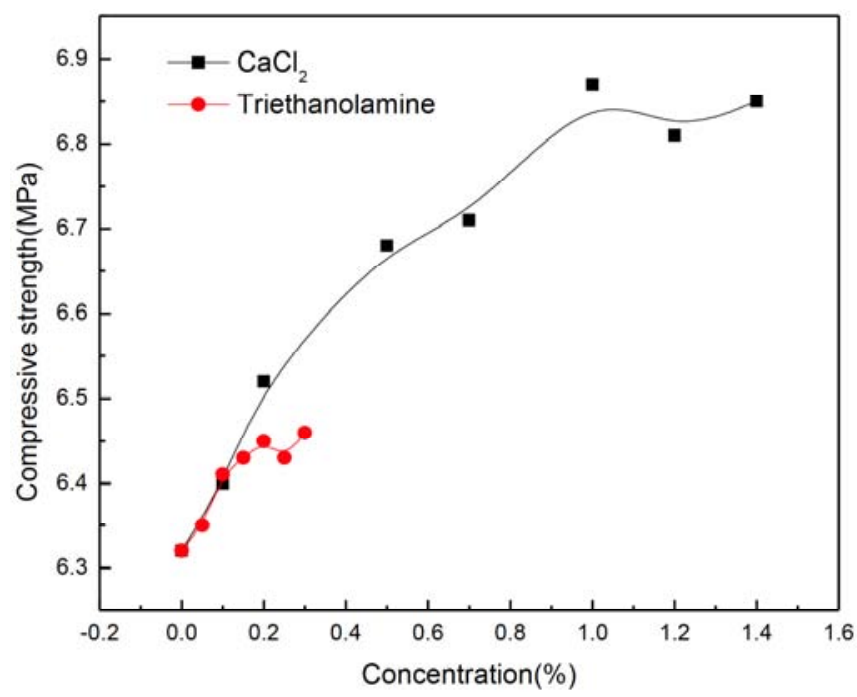

Fig. (1). Compressive strength of the cementing body formed by a mixture of different additives.

Table 7. The Compressive Strength of the Cementing Body Formed by a Mixture of the Self-Binding Agent $(\leq \mathbf{0 . 1 5} \mathrm{mm})$ and Different Additives (MPa)

\begin{tabular}{|c|c|}
\hline Additives & Compressive Strength \\
\hline \hline$/$ & 6.32 \\
\hline $1.0 \% \mathrm{CaCl}_{2}$ & 6.87 \\
\hline $0.2 \%$ Triethanolamine & 6.45 \\
\hline $1.0 \% \mathrm{CaCl}_{2}+0.2 \%$ Triethanolamine & 6.98 \\
\hline
\end{tabular}

\subsection{Binding to the Formation Rocks}

The agent was mixed with sandstone, mud shale, or limestone $(0.2-0.4 \mathrm{~mm})$ at a mass ratio of $8: 2$ for consolidation at $90^{\circ} \mathrm{C}$, and the results are shown in Table 8 . It is clear that the compressive strength of the cementing body is largely comparable with that formed by the agent alone, indicating that a small quantity of the sandstone, mud shale, or limestone has essentially only a minor effect on the compressive strength of the cementing body, as shown in Fig. (1). It is observed that the hydrolysis products enable the agent to bond tightly to the rock particles tested.
Table 8. Compressive Strength of the Cementing Body formed By the Self-Binding Agent $(\mathrm{d} \leq 0.15 \mathrm{~mm})$ Mixed with Rocks (0.2-0.4 mm) at 90 ${ }^{\circ} \mathrm{C}(\mathrm{MPa})$

\begin{tabular}{|c|c|c|c|}
\hline Time & Sandstone & Mud Shale & Limestone \\
\hline \hline $2 \mathrm{~h}$ & 8.97 & 9.11 & 8.95 \\
\hline $4 \mathrm{~h}$ & 10.05 & 9.87 & 9.79 \\
\hline
\end{tabular}

\subsection{Stability of the Cementing Body}

Whether the cementing body can sustain for a long period of time or has not potential implications for the practicality and effectiveness of this agent. The cementing body formed at $50^{\circ} \mathrm{C}$ for $24 \mathrm{~h}$ was immersed in water for aging test in an incubator at $80^{\circ} \mathrm{C}$ or $120^{\circ} \mathrm{C}$. Three samples were taken out at an interval of $5 \mathrm{~d}$ and then dried to determine their compressive strength, and the results are shown in Fig. (2). It is evident that the compressive strength hardly changes with time, suggesting a high stability of the cementing body formed under the aforementioned condition.

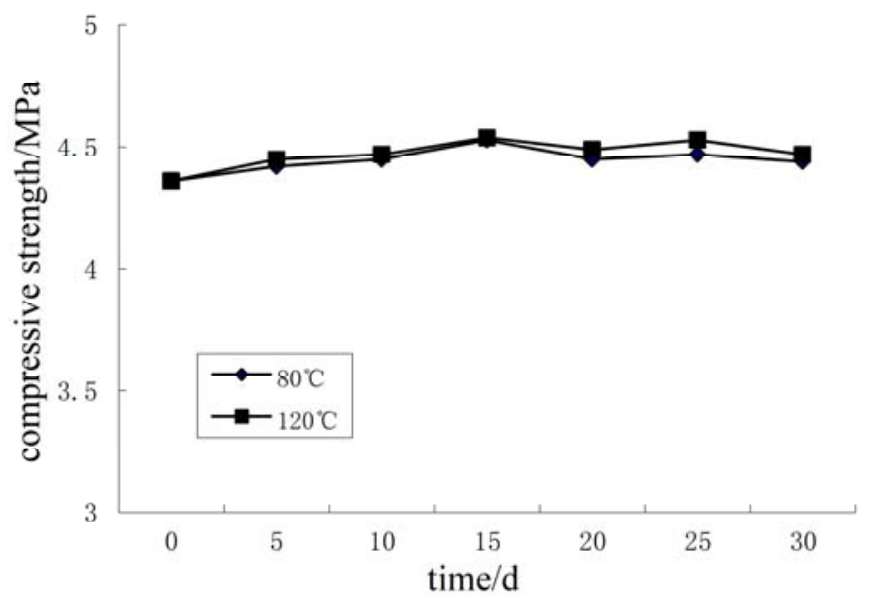

Fig. (2). Compressive strength of the cementing body as a function of time.

\section{PERMEABILITY OF THE CEMENTING BODY}

When used for lost circulation in oil reservoir, the cementing body is preferably permeable to some extent so that production will be less affected. The agent with different particle sizes, $0.4-0.6 \mathrm{~mm}, 0.6-0.8 \mathrm{~mm}, 0.8-1.0 \mathrm{~mm}$, or 1.0 $1.2 \mathrm{~mm}$, were consolidated at $50^{\circ} \mathrm{C}$ for $24 \mathrm{~h}$. The variations of the permeability and compressive strength of the cementing body as a function of the particle sizes of the agent are shown in Figs. $(\mathbf{3}, \mathbf{4})$, respectively. The permeability increases with increasing particle sizes of the agent, as shown in Fig. (3), whereas the opposite is true for the compressive strength, as shown in Fig. (4). Preferably the agent is of a proper particle size distribution so as to trade off the permeability and the compressive strength, that is, to effectively control the lost circulation while not block the oil reservoir completely. It is suggested that the particle size of the agent is preferably within the range of $0.1-0.7 \mathrm{~mm}$, which 
will lead to a rapid consolidation rate and a high compressive strength and permeability of the cementing body.

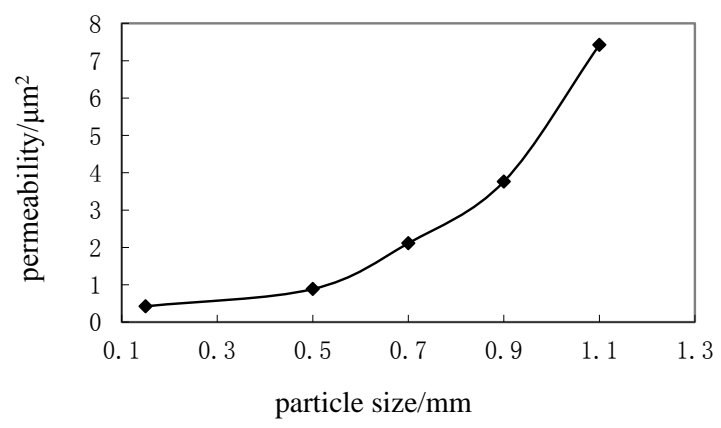

Fig. (3). Effect of particle sizes of the self-binding agent on the permeability of the cementing body formed.

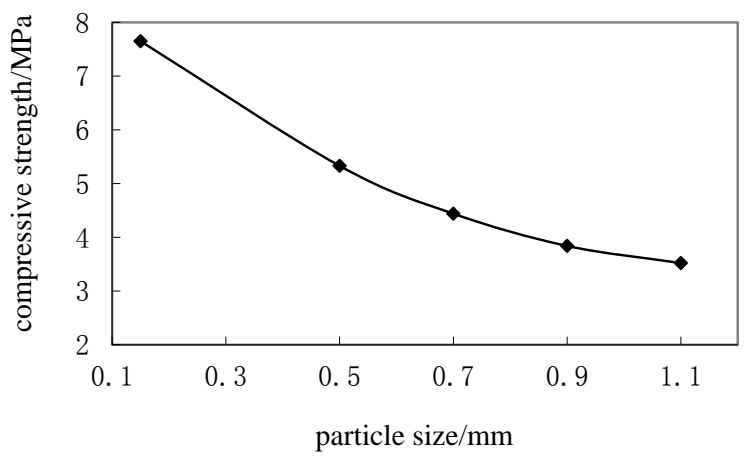

Fig. (4). Effect of particle sizes of the self-binding agent on the compressive strength of the cementing body formed.

\section{COMPARISON WITH OTHER LOST CIRCU- LATION AGENT}

With the increase of drilling period, conventional plugging materials such as shells, fiber happens deformation, degradation and decreasing of strength and makes the plugging failure. After injecting into the formation, cement plugging agents diluted by water extended the clotting time and affect plugging result. Comparative evaluation of the high strength resin plugging agent and compressive strength of the cement plugging agents was shown in Table 9. As can be seen from the test results, the compressive strength of cement plugging agents was higher than the compressive strength of bridge plugging agent. But compared with selfbinding agent, they were still low.

Table 9. Compressive Strength of Different Types of Lost Circulation Agent with the Change in Time and Temperature

\begin{tabular}{|c|c|c|c|c|}
\hline & \multicolumn{4}{|c|}{ Temperature $\left({ }^{\circ} \mathbf{C}\right)$} \\
\cline { 2 - 5 } & $\mathbf{5 0}$ & $\mathbf{7 0}$ & $\mathbf{9 0}$ & $\mathbf{1 2 0}$ \\
\hline \hline self-bonding agent & 4.32 & 5.34 & 5.41 & 5.73 \\
\hline cement & 4.33 & 4.41 & 4.36 & 4.35 \\
\hline bridge circulation agent & 3.2 & 2.84 & 2.1 & 0.89 \\
\hline
\end{tabular}

\section{MECHANISM OF CONSOLIDATION OF THE SELF-BINDING AGENT}

\subsection{Hydrolysis Characteristics}

The self-binding agent is primarily composed of anhydrous calcium aluminosulphate $\left(3 \mathrm{CaO} \cdot 3 \mathrm{Al}_{2} \mathrm{O}_{3} \cdot \mathrm{CaSO}_{4}\right)$ and dicalcium silicate $\left(2 \mathrm{CaO} \cdot \mathrm{SiO}_{2}\right)$, which are hydraulic materials that can react with water to form cementitious compounds and later harden into a strong rocklike solid. Initially, the agent dissolves via a dissolution-precipitation reaction with the formation of ettringite $\left(3 \mathrm{CaO} \cdot \mathrm{Al}_{2} \mathrm{O}_{3} \cdot 3 \mathrm{CaSO}_{4} \cdot 32 \mathrm{H}_{2} \mathrm{O}\right)$, aluminium hydroxide $\left(\mathrm{Al}_{2} \mathrm{O}_{3} \cdot 3 \mathrm{H}_{2} \mathrm{O}\right)$ gel, and calcium silicate hydrate $\left(2 \mathrm{CaO} \cdot \mathrm{SiO}_{2}\right.$. $\left.\mathrm{H}_{2} \mathrm{O}\right)$ gel. The reaction formula is A. Hydrolysis process:

$\left(3 \mathrm{CaO} \cdot 3 \mathrm{Al}_{2} \mathrm{O}_{3} \cdot \mathrm{CaSO}_{4}+2\left(\mathrm{CaSO}_{4} \cdot 2 \mathrm{H}_{2} \mathrm{O}\right)+34 \mathrm{H}_{2} \mathrm{O} \rightarrow\right.$

$3 \mathrm{CaO} \cdot \mathrm{Al}_{2} \mathrm{O}_{3} \cdot 3 \mathrm{CaSO}_{4} \cdot 32 \mathrm{H}_{2} \mathrm{O}+2\left(\mathrm{Al}_{2} \mathrm{O}_{3} \cdot 3 \mathrm{H}_{2} \mathrm{O}\right)$

$2 \mathrm{CaO} \cdot \mathrm{SiO}_{2}+2 \mathrm{H}_{2} \mathrm{O} \rightarrow 2 \mathrm{CaO} \cdot \mathrm{SiO}_{2}-\mathrm{H}_{2} \mathrm{O}+\mathrm{Ca}(\mathrm{OH})_{2}$

One of the hydrates of dicalcium silicate, $\mathrm{Ca}(\mathrm{OH})_{2}$, can react with aluminium hydroxide gel and gypsum to form ettringite according to the following reaction formula:

$3 \mathrm{Ca}(\mathrm{OH})_{2}+3\left(\mathrm{CaSO}_{4} \cdot 2 \mathrm{H}_{2} \mathrm{O}\right)+\mathrm{Al}_{2} \mathrm{O}_{3} \cdot 3 \mathrm{H}_{2} \mathrm{O}+20 \mathrm{H}_{2} \mathrm{O}$

$\rightarrow 3 \mathrm{CaO} \cdot \mathrm{Al}_{2} \mathrm{O}_{3} \cdot 3 \mathrm{CaSO}_{4} \cdot 32 \mathrm{H}_{2} \mathrm{O}$

The ettringite can act as a solid skeleton, which will be filled and strengthened with aluminium hydroxide gel and calcium silicate hydrate gel.

\subsection{Consolidation Process}

When final setting is obtained, the hydrolysis of the selfbinding agent continues, in which an increased amount of ettringite, aluminium hydroxide gel, and calcium silicate hydrate gel are produced as small fibrous crystals on the surface of the agent. These fibrous crystals, just like chains, can bind the particles tightly together, thus enabling the selfbinding agent that previously has no mechanical strength to be hardened into rocklike solids.

\subsection{Microstructure of the Cementing Body}

Scanning electron microscopy was applied to observe the microstructure of the cementing body formed by the selfbinding agent, and the resulting SEM pictures are presented in Fig. (5). It shows that the reaction products of the agent are needle-like or flat, which will bind the self-binding agent together to form cementing body.

\section{CONCLUSIONS}

This study presents a novel self-binding lost circulation agent with some distinct advantages that make it suitable for use in controlling severe lost circulation:

This agent is a granular solid with irregular shape, and particles do not react with each other. According to the actual condition of loss formation the product can be used with different sizes and distribution and it can bridge or fill the cracks, crevices, fissures, and other porous or faulty formations into which the drilling fluid is lost and can effectively plug leakage channel. Its density is $1.075 \mathrm{~g} / \mathrm{cm}^{3}$. 

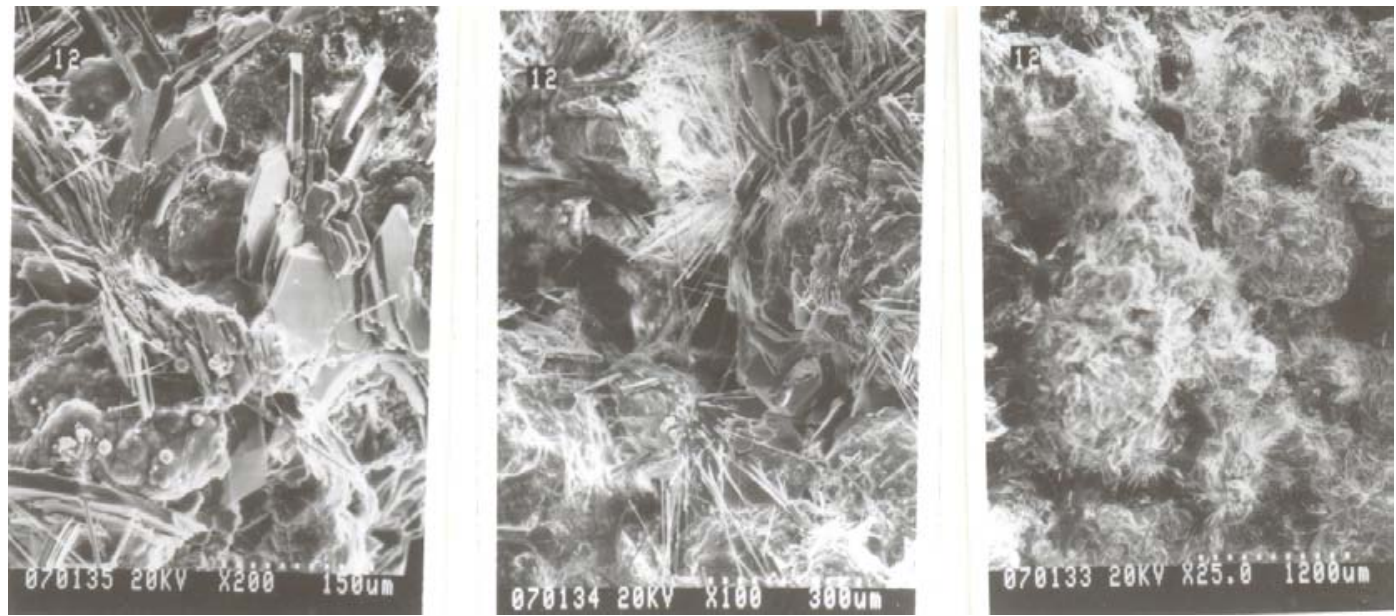

Fig. (5). SEM picture of the cementing body formed by the self-binding agent.

(2) This agent mainly consists of anhydrous calcium sulphoaluminate and dicalcium silicate and it will undergo a chemical reaction with water, and the reaction products are needle-like or flat that can bind the particles together, thus enabling the self-binding agent that previously has no mechanical strength to be hardened into a rocklike solid. The consolidating rate and compressive strength of the cementing body is affected by temperature, particle sizes and additives. The results shows that the higher the water temperature, the more conducive to the consolidation; The longer the curing time, the better the consolidation; The smaller the agent, the more conducive to the consolidation and can greatly reduce the cementing time and increase the strength of the cementing body; The addition of additives can also accelerate the hydrolysis solidification and increase the strength of the cementing body.

(3) The cementing body formed by the agent has high stability and with the increase of storing time its compressive strength changes little. Experiment of binding to the formation rocks shows sandstone, mud shale, or limestone can bond with the new type of chemical lost circulation agent firmly. The cementing body has certain permeability, which, however, varies as a function of the particle size of the agent. Thus this agent is proper for use in lost circulation in oil wells.

\section{CONFLICT OF INTEREST}

The authors confirm that this article content has no conflict of interest.

\section{ACKNOWLEDGEMENTS}

Declared none.

\section{REFERENCES}

[1] Bannerman, M.; Chevron, J. New API Practices for Isolating Potential Flow Zones During Drilling and Cementing Operations., SPE Annual Technical Conference and Exhibition, 9-12 October 2005; Society of Petroleum Engineers: Texas, U.S.A., 2005.
[2] Amanullah, M.D. Experimental Evaluation of FormationStrengthening Potential of a Novel Gel System. IADC/SPE Asia Pacific Drilling Technology Conference and Exhibition, 13-15 November 2006; Society of Petroleum Engineers: Bangkok, Thailand., 2006.

[3] Hong-feng, G.; Zhen-shan, B.; Chang-qing, Q. Research on bridge plugging technology and blocking agents. Petrol. Drill. Technol., 2000, 5, 39-40.

[4] Hong-li, Z.; Yan, G.; Zhi-long, W. Lost circulation materials in china. Spec. Oil. Gas. Reserv., 2004, 2, 1-2.

[5] Xi-wen, Z.; Shuang, L.; Jie, Z. Research progress on lost circulation materials and lost circulation control technology. Drill. Fluid. Compl. Fluid. 2009, 6, 74-76.

[6] Xiong-hu, Z.; Feng-chun, W. Research Development of Waste Drilling Fluids Disposal. Drill. Fluid. Compl. Fluid., 2004, 2, $45-$ 50.

[7] Marriott, T.; Griffith, J. Foamed conventional lightweight cement slurry for ultralow density and low ecds solves lost-circulation problem across coal formations: A Case History. SPE Annual Technical Conference and Exhibition, 9-12 October 2005; Society of Petroleum Engineers: Texas, USA, 2005.

[8] Bruton, J. R.; Ivan, C. D.; Heinz, T. J. Lost circulation control: evolving techniques and strategies to reduce downhole mud losses. SPE/IADC Drilling Conference, 27 February-1 March 2001, Society of Petroleum Engineers: Amsterdam, Netherlands., 2001.

[9] Zai-ming, W.; Zheng-song, Q.; Jia-fang, X. Balance area of compound lost circulation control and its application in novel lost circulation simulator. Acta. Petrol. Sin., 2007, 28(1),143-145.

[10] Tong-tai, X.; Xu-jie, L.; Wei, S. Technology of lost circulation resistance and control during drilling engineering; Petroleum Insdustry Press: Beijing, 1997, pp. 217-220.

[11] Bin, W.; Jie-nian, Y.; Sheng-li, Z. Formation damage control technology for fractured reservoir in TARIN oilfield. J. Univ. Petrol., 2002, 26(1), 32-34..

[12] Dai-jun, Z. Application of lost circulation prevention and control technology for superhigh pressure Yangdu-3 well. Nat Gas Indus. 2000, 20(4), 33-36.

[13] Jie-nian, Y., Ed. Drilling Fluid Technology. Dongying; The Press of University of Petroleum: China, 2001, pp. 358-359.

[14] Gelan, E. L.; David, A. G. design and evaluation of lost-circulation materials for severe environments. J. Petrol. Technol., 1990, 44, 328-337.

[15] Li-xin, H.; Guang-ming, Z. Mechanism of pore throat's plugging due to solid particles in a formation. J. Jianghan. Petrol. Inst., 1999, 21(2), 41-43.

[16] Labenski, F.; Reid, P.; Stantos, H., Eds. Drilling fluids approaches for control of wellbore instability in fractured formations. SPE/IADC Middle East Drilling Technology Conference And Exhibition, SPE 85304, Abu Dhabi, United Arab Emirates 20-22 October 2003, 2003, 134-145.

[17] Cui Ying-chun, Zhang Yan. Application of fractal theometry theory to optimal selection of temporary plugging agents. J. Univ. Petrol., 2000, 24(2), 17-20. 
[18] Ming-you, Z.; Xiao-bing, S.; Min-jie, W. Application of drilling fluid shielding and temporary block technology in SHIZIGOU oilfield. J. Southwest Petrol. Inst., 2006, 28(4), 67-70.
[19] Liu Ai-jun. Study on the new techniques of superior shielding and temporary plugging drill-in fluids. J. Shandong. Inst. Build. Mater., 2003, 17(1), 83-86.

(C) Lv et al.; Licensee Bentham Open.

This is an open access article licensed under the terms of the Creative Commons Attribution Non-Commercial License (http://creativecommons.org/licenses/by-nc/3.0/) which permits unrestricted, non-commercial use, distribution and reproduction in any medium, provided the work is properly cited. 